\title{
BREAKING THE BARRIERS OF RESEARCH WRITING: RETHINKING PEDAGOGY FOR ENGINEERING GRADUATE RESEARCH
}

\author{
Janna Rosales $^{1 *}$, Cecilia Moloney ${ }^{1}$, Cecile Badenhorst ${ }^{2}$, Jennifer Dyer ${ }^{3}$ and Morgan Murray ${ }^{4}$ \\ ${ }^{1}$ Faculty of Engineering and Applied Science \\ ${ }^{2}$ Faculty of Education \\ ${ }^{3}$ Graduate Program in Humanities, Faculty of Arts \\ Memorial University, St. John’s, NL \\ and \\ ${ }^{4}$ Words in Edgewise, St. John's, NL \\ *Corresponding Author E-mail Address: jrosales@mun.ca
}

\begin{abstract}
A key attribute for success in graduate studies is the ability to conduct research and to communicate research effectively. However, many researchers in engineering do not identify as writers, regarding research writing as the end product of a static template. Novice and experienced researchers alike encounter problems common to all writers such as writer's block and procrastination, and struggle for clarity of thought and brevity of message.

Conventional, skills-based support for research writing exists at many universities, but an interdisciplinary research team at Memorial University has been investigating more integrative and innovative ways to break down barriers to thinking and writing clearly about research, particularly for engineering graduate students. Using the lens of academic literacies, this paper presents "Thinking Creatively about Research," a research project that developed and piloted a multi-day, co-curricular workshop for engineering graduate students at Memorial University. Preliminary findings indicate that the workshop pedagogy can transform student perspectives of research and writing.
\end{abstract}

Keywords: academic literacy; academic writing; graduate engineering education; graduate research writing; creativity; transformative education

\section{INTRODUCTION}

\subsection{The Need and the Context}

"Any time you start a new writing project, you embark on a new journey." This quote points to the heroic journey metaphor for dissertation writing [4], which highlights the difficulty that many people have with the process of writing, as well as one of the its reasons.
Readers who have written a graduate dissertation, for example, may resonate with the journey metaphor, as their memories map the unique circumstances of their thesis writing experience. Indeed, writing of all kinds is hard. Moreover, for academic or research writing, the identity or the student or researcher is bound up with his or her writing output and its formal evaluation in courses and through peer and funding reviews $[3,4]$.

A key attribute for success in graduate education in post-secondary contexts is the ability to conduct research and to communicate research effectively. Written expression is the lifeblood of academic research, but many researchers in engineering and science do not necessarily identify as writers, regarding engineering and scientific research writing to be the end product of a static template. Once they have reached a certain level of proficiency with academic writing, many researchers neglect to continue to develop their writing skills or to explore their identity as a writer. Even so, novice and experienced researchers alike typically encounter barriers common to all writers such as writer's block and procrastination, as well as the struggle to achieve clarity of thought and brevity of message.

Few universities offer formal (or even informal) programming for graduate students to help them to tap into and nurture the creative aspects of thinking about and writing about their academic research. Although many universities offer writing courses and programs, and many resource books on writing for academics are available, these tend to emphasize skills-based approaches to writing. There has been much less emphasis on the creative aspects of writing in research, on writing as a process, or on writing as a social practice within a community of discourse.

An interdisciplinary research team at Memorial University has been investigating more integrative and innovative ways to break down barriers to thinking and 
writing clearly about research. The authors of this paper conducted a project 2011-2012, named “Thinking Creatively About Research", as a pilot co-curricular program which offers research writing workshops that embody the above values and elements. The pilot workshops were offered to graduate students in Humanities and Arts (Fall 2011) and in Engineering and Applied Science (Winter 2012). Along with the operational workshops of the pilot program, we are conducting a research study to assess the outcomes and effectiveness of the approach.

The "Thinking Creatively About Research" program offered this year at Memorial University is founded on a significant base of past experience and relevant expertise within the project team, as well as on past materials developed to foster research writing. The workshops are structured around a book by one of the team, Cecile Badenhorst, Research writing: Breaking the barriers [3] and other materials developed and field tested extensively through workshops for faculty members and graduate students in the South African university context. In addition, the workshops and the accompanying research study benefit from the interdisciplinary nature of the team, and from expertise and experience pertinent to the project, notably in: dialogue, contemplative education, and leadership development (Rosales); fostering thinking about research and research writing in engineering [20] (Moloney); creativity studies (Dyer); and interdisciplinary research and writing (Murray).

\subsection{Purpose and Research Goals}

The purpose of the "Thinking Creatively about Research" pilot program was to offer workshops to enhance the self-efficacy, confidence and productivity of graduate students for writing academic papers and dissertations. The key purpose of the accompanying research study was to study the workshop pedagogy for its effectiveness in transforming student perspectives of research and writing.

In order to examine how that transformation occurs, we are guided by three main pedagogical questions:

1. What does the writer need to know about research/academic discourse?

2. What does the writer need to understand about writing/creativity?

3. What does the writer need to know about him/herself as a researcher/writer?

The research study is structured as an interpretive qualitative research study [18] with three stages:

o Stage 1: Conducting the workshops themselves;

o Stage 2: Workshop data collection (samples of student work; surveys and program evaluations);

o Stage 3: Longitudinal data collection to explore the effects of the workshop intervention over time.
A thread weaves through the entire project based on repeated sampling of participants' self-identifications as research writers through free-writes starting with " $I$ am the kind of writer who...." Participants are invited to reflect on how these statements and their selfidentifications change over time. This repeated activity leads to revisions (i.e. re-visionings) by the participants not only of their current writing project(s), but also revisionings of themselves and their relationship to their community of academic discourse.

Using the lens of academic literacies, this paper discusses the preliminary findings of "Thinking Creatively about Research" for engineering graduate students. The paper outlines the background of our approach in academic literacies and describes the structure and dynamic of the workshops. The research data collected during the workshops allows us to examine the pedagogy of research writing for its efficacy in transforming graduate student perspectives on research and writing.

\section{BACKGROUND}

\subsection{Academic Literacies}

'Academic literacies' is the term used to describe a philosophical shift in perspective about how to approach student academic writing in post-secondary contexts. The concept comes from Lea and Street [11-15, 24-26] who argued that institutions, faculty and students have different approaches to student writing. These different approaches are effectively epistemologies about academic writing. Lea and Street identified three different approaches to writing: 1) a skills approach; 2) a process approach, also called academic socialization; and 3) an academic literacies approach.

According to the skills approach, writing is seen as a generic cognitive individual skill. If a student cannot write in an academic context, it is because he or she has not acquired the necessary skills. The assumption is that if a student takes a course on academic writing, he or she will be able to take that 'skill' and write in any context or discipline. What underlies this perspective is a deficit model of academic writing. The student is at fault for not having the required skills.

The process or academic socialization approach suggests that writing is not a skill that can be acquired generically but is tied to particular disciplines or contexts. This approach acknowledges that disciplines have particular writing genres and ways of using language. For students to become successful writers, they need to learn the language of the discipline and become socialized into the discourse.

The third approach, academic literacies, is substantially different from the previous two. Academic 
literacies takes the view that writing in an academic context is complex and unstable. Writing is about learning an identity. For example, for an engineer or a scientist, writing involves negotiating ever changing disciplinary requirements and developing authority in a particular context. The context is always situated in time and place and as such, always shifting. The term 'literacies' acknowledges that academic writing encompasses more than just writing. A student will need critical literacy, visual literacy, research literacy, information literacy and so on, to be a successful writer. A key component of the critical literacies approach is that students develop a critical awareness of disciplinary language, knowledge, and their position in the discourse. From this perspective, writing is something that students acquire over time and with practice by participating in the discipline.

In the “Thinking Creatively about Research" project, we used an academic literacies approach by being explicit in our instruction on reading and writing. Clarifying the expectations and inherent assumptions of academic discourse helped to demystify the research process and enabled students to critically examine the discourse and underlying power structures in their discipline and then to work out their own ways to write with authority.

\subsection{Engineering Research Writing}

It is widely acknowledged in engineering that writing well is important for success in an engineering career [17], and clearly this holds also for engineering graduate studies and in engineering research careers. To be successful in research, it is not enough just to publish papers; to be successful, you must have those papers cited by others and write proposals that get funding [16,23].

Currently, the dominant method for teaching research writing or for passing along research writing techniques is via the apprenticeship model of graduate student supervision. The apprenticeship model can work well, when the supervisor is a good writer and interested both in writing and assisting his or her students to become better writers, and when the student is comfortable in the apprenticeship role. A second method by which graduate students learn to write is by reading well-written research papers and modeling their writing off these papers. However, both approaches to research writing can be problematic when the conditions are not optimal: when supervisors themselves are not good writers [5]; when students have not been introduced to reading critically and assessing the writing quality in the papers they read in their research [10]; or when students lose confidence in their writing due to concerns about their basic language skills or about being able to write the highly stylized language of engineering and science papers [5,21,27].
A compounding problem is that many engineering researchers tend to think about writing as a separate, and later, stage from that of doing research proper. Engineering researchers sometimes speak of "writing up" their research, as though the writing followed the research as a straightforward and simple process [23]. Others fall into the fallacy of thinking that their results speak for themselves, or tend to write as if for themselves rather than for other readers [16].

Numerous textbooks and resources are available for the novice engineering writer, but many of these tend to reinforce the "writing up" model of research writing, by outlining how to structure a paper and giving tips on how to write paragraphs, sentences, etc. That is, they focus on tools or skills, rather than on the process of writing, or on writing as an integral part of research.

However, within the long shelf of books and papers on technical writing, there are some notable authors who express other views about writing in engineering (or in science). These are, variously: that writing engineering is a creative process; that writing engineering is storytelling; that writing is itself part of research, and thus that writing is thinking [2,21,23,27]. Moreover, these authors also promote the value (in terms of career and research success) of becoming a writer, and for that, coming to self-identify as a writer is important.

Research in graduate pedagogy suggests that neither the traditional immersion or apprenticeship model of graduates studies (with writing instruction being implicit, except in rare cases), nor lists of formulaic advice or of best practices, is serving graduate students well [1,5]. Thus, universities should promote pedagogies of explicit instruction in research writing [5].

Such pedagogies need to be based on an understanding that research writing is a social practice, and that good writing needs to be situated in the discourse of a particular discipline, rather than generic across disciplines $[5,7]$. At the same time, research writing is a creative process. Thus, we need pedagogies which foster selfidentification of the researcher as writer, and which assist novice researchers to position their research within wider perspectives of both self and technical context, in part by cross-disciplinary and cross-model activities such as freewriting and sketching, etc. [19,23]. Thus, such a pedagogy of research writing in engineering would be both discipline-specific and interdisciplinary; in other words, it would be a pedagogy of academic literacies.

\section{THINKING CREATIVELY ABOUT RESEARCH}

"Thinking Creatively about Research" is an intensive, multi-day, co-curricular workshop that seeks to break down the barriers of real and perceived writing 
restrictions. It is grounded in a pedagogy of transformation and change in higher education; this curriculum was captured in a book [3] and the workshops at Memorial University were adapted from this source. The pilot offering of the workshop was conducted with a small, volunteer cohort of students from Memorial University's Graduate Program in Humanities and the Faculty of Arts in Fall 2011, while the second offering occurred in Winter 2012 with graduate students from the Faculty of Engineering and Applied Science.

Regardless of the student's discipline and stage of research, the program guides the participant through the process of research writing, from conceptualizing his or her research question to revising the final draft. While some tailoring of the workshop materials occurred for the second offering to make the experience most relevant to engineering (e.g. research genres in engineering, choice of sample research papers, etc.), the creative exercises were repeated from the workshops offered to the Humanities and Arts students in Fall 2011.

Each offering of the workshop involved seven mornings of instruction which lasted 3.5 hours each. The workshop is divided into two parts to simulate the two stages of the writing process: composition (Part 1, four consecutive mornings) and revision (Part 2, three consecutive mornings), with daily homework assigned to reinforce key learning points. Between these two sessions, participants had approximately a month to work on the first draft of their chosen research writing.

Each of the seven workshop mornings was divided into two sections. In the first section, activities and facilitated dialogue would give participants information on academic discourses (e.g. what counts as evidence in engineering, how arguments work, research writing genres, etc.) and they would be guided through theories on writing (e.g. writing as process, what goes into different forms of writing, why writing is difficult, how self-criticism can be crippling, how to deal with procrastination, how academic writing is situated in a discourse of criticism, what constitutes a writing identify, etc.). Following a nutrition break, the second half of each morning included 'play' activities intended to allow, and even encourage, participants to move out of their usual way of writing and thinking, and to foster the growth of a community in the workshop.

The sessions were facilitated by Cecile Badenhorst, with the other team members present as observerparticipants per Merriam's research methodology (see “Being a careful observer", Chapter 6 of [18]).

In addition to the text by Badenhorst [3] which was supplied to all participants, other articles on writing or on research success were recommended, e.g. [2,8,9,10,16,22], as well as online resources, e.g. [7].

Data for the research component of "Thinking Creatively about Research" were collected during the workshop sessions (i.e. reflections written by participants; free-writing, sketching and concept-mapping activities) and by surveys and program evaluations at the end of each part. We have recruited a subset of the participants who have consented to take part in a longitudinal study intended to assess the longer-term effects of the pedagogy.

The focus of this paper is on the experience and preliminary results of the Engineering version of the workshop; the first half of the workshop was conducted January 30-February 2, 2012 and the second half was conducted February 27-29, 2012.

\section{RESULTS AND DISCUSSION}

\subsection{Programmatic Results}

Although the workshop participants found the time commitment to be challenging in the midst of the Winter semester, 13 participants completed the full set of engineering workshop sessions out of the 17 who registered. (Note that completion here means participation in at least 5 of the 7 mornings; this also qualified the students for an entry on their co-curricular record). This is a significant rate of completion for a co-curricular program with 25 contact hours and additional homework, i.e. over half of the time commitment for a credit course. Of those who missed sessions or did not complete the entire program, some cited conflicts with classes, meetings with supervisors and other work commitments such as teaching and lab duties as teaching assistants.

Those who did complete the workshops were enthusiastic and committed. The research data collected shows growth in writing output, confidence and selfidentification as a writer over the course of the workshop

\subsection{Themes within Individual Results}

Much could be written about the findings of the "Thinking Creatively about Research" workshop, the engineering participants, and the pedagogy employed. Indeed we are still collecting data from a longitudinal part of the research study, and have more analysis to do, especially as concerns the cross-disciplinary analysis. This paper will focus on four themes which emerge from the engineering research findings: self-identification as a writer; the role and value of explicit instruction; the element of play; and how the former elements fostered transformative learning.

4.2.1 Self-Identification as a Writer. Although written expression is essential in academic research, many researchers in engineering and science do not necessarily identify as writers. The workshop was book-ended by two 
reflection free-writes to benchmark where students were at the start, and then at the end, of the workshop. The first reflection was written at the start of Day One, on "I am the kind of writer who...", and the second on Day Seven on "I am now the kind of writer who ...".

The Day One "I am the kind of writer who..." exercise was intended to allow students to self-identify, to tap into their assumptions about the writing process and their personal experience with writing. Of note is that the students frequently used the word 'not' and other negatives in these free-writes. For example,

- "I am the kind of writer who is not good at explaining my work to others.” (d1-1)

- "I am the kind of writer who cannot write easily, almost I cannot arrange my ideas correctly and sometimes I cannot explain my ideas clearly." (e1-1)

Others were more positive, but still expressed the struggle of writing:

- "I'm the kind of writer who thinks a lot before starting to write. It takes me more [time] than I think I should to do corrections and modifications on my writing. I find writing sometimes is a challenge to me, although I do enjoy the process of writing." (a1-1)

One student expressed a discomfort with revision, "I am the kind of writer who doesn't like to revise [my] writing after writing the draft. But I have to do it." (n1-1)

By way of contrast with these self-reflections, a second free-write on Day One asked participants to comment on their understanding of the standard of writing in engineering, by starting, "Good engineering research writing is..." This exercise elicited the views that good engineering research writing is:

logical; structured; unambiguous, clear, simple, concise, focused; easy to understand; practical; insightful; detailed; precise; coherent; enjoyable; easy to read; has a clear problem statement and purpose; has well supported conclusions; uses a variety of techniques to describe and explain: charts, graphs, tables, figures; presents detailed data/concepts in simple ways; flows; provides effective summary; tells a research story.

This long list demands clarity and knowledge on the part of the writer. Certainly writing to these standards would seem to be difficult to accomplish, consistent with the tone of the Day One free-writes on "I am the kind of writer who...”.

By Day Seven, the overall tone of the self-reflections had changed. The free-writes for "I am now the kind of writer who..." contained fewer negatives, and the reflections were longer, and more oriented towards a future of more productive writing. For example:

- "I feel more comfortable with writing, and I can start writing more easily. It does not take much time for me to think before writing." (d7-2)
- "I am now the kind of writer who knows how to start something big in a planned way. I still procrastinate for some reasons, but I know some strategies to deal with it. I want to start my writing with a simple piece of free writing. Then gradually, I map my writing and have my idea well organized." (a7-2)

- "I am now the kind of writer who has improved my writing. I used to like to plan well before I start to write. Now, I learned to do some "adventure" things also like "bungee jumping" before I begin the former writing. I believe that if I can combine these two well, I will reach a higher level in writing." (i7-2)

Even the participant who didn't like to revise his first draft now saw his way to doing so:

- "I am now the kind of writer who still doesn't like to revise what I wrote, but now I am less stressed about it because it is easier after learning how to revise it with different rounds. And of course a better writing in the first place for draft1." (n7-2)

At the end of the workshop Day Seven, students were invited to compare their Days One and Seven pair of freewrites on their self-identification as writers and to draw their own conclusions on their personal growth in confidence and self-awareness.

4.2.2 Explicit Instruction. Although engineering education tends to be very explicit in regards to technical ideas, many process aspects of education tend to be implicit. This is particularly so with regards to research writing. In the workshops, the often hidden rules of academic discourse were explicitly discussed, so that participants felt empowered to make more informed choices about how they think about and communicate their work. For example:

- "I used to have the same strategy in my writing; however, this was intuitive or done in a common sense way. So, it was good to find/know a scientific or a guided way to do my PS." (m2-1)

- "The PPS was helpful to me. Although I had many comments from my supervisor regarding my writing, yesterday I got some general rules which I think will help me in the future." (e2-1)

- "Now I have some strategies to follow when I am starting to write. For example, I start with the PPS\&Q, then make my main claim, break down the main claim into a few subclaims, find evidence to support. By this time, I have the bare bones already. The next step is to make the story smooth and easy to follow. By repeating this, it comes closer to the finish." (a4-1)

[In the above quotes, PPS\&Q, as well as PS and PPS, refers to 'Problem and Purpose Statement with Questions,' a key technique in the workshop Likewise, 'bare bones' is one of the workshop techniques.] 
4.2.3 The Element of Play. "Optimal experience," according to psychologist Mihaly Csikszentmihalyi, happens when people experience feelings of intense concentration and deep enjoyment [6]. Many academic writers face challenges throughout the research process, and moments of optimal experience may seem far too elusive. The workshops were intended to empower researchers of all levels and backgrounds to connect more consistently with the source of that creative flow. Doing so was through the element of play which was incorporated into the workshops, both through specific activities, and throughout the workshop in the non-regular layout of furniture, the use of coloured paper and pens, etc., and in the serious yet relaxed tone fostered by the facilitators.

For example, an activity on Day Two asked the participants to free-write on "I am the colour of...". The results were interesting. The responses were weighted towards the colour of blue, as the sky and the ocean, although other colours were also cited. Although there seemed to be some reluctance initially to the exercise (puzzled looks, questions for clarifications), the freewrites which emerged were equally creative and poetic to those of the Humanities and Arts cohort. In fact, this freewrite may have been a crucial turning point in the Engineering workshop. The group began to see themselves more as writers after sharing their first explicitly personal and creative piece of writing. After this, there was more trust, cohesion, and playfulness in the group, whether working on "serious" writes for their research, or in the deliberately playful activities which ended each day.

Later, near the end of the workshop, on Day Seven, participants were asked to comment on the element of play in the workshop. Some responses are:

- "The element of 'play' makes work more interesting. We think in a different way, work in a different way, and it opens our mind, we are able to get more ideas." (d7-1)

- "Element of play was really good. It is the same as children: they learn easier and better when they play. When you learn during play, you don't feel you are making effort to learn anything." (b7-1)

- "Some of the play seems not closely related to writing at the first glance, but after reflection on it, I find the questions asked are quite relevant to writing. These questions make me think more about my research and my writing from a different perspective." (a7-1)

- "Coloured paper, pens, graphs, pushing boundaries... I would say I enjoy using these elements. It [lets] me feel relax when I am dealing with serious research problems. They also show me that research topic can also be fun. But I am not sure I can use them all the time. It just takes time for me to get used to it." (k7-1)
4.2.4 Transformative learning. Finally, we were interested to find evidence that the approach was making a difference in how well participants wrote, both in the quality of the writing experience and in the quality and quantity of the writing output. Transformative learning is very difficult to measure, and we would not want to claim that a seven-morning workshop experience could lead to significant changes. But we can be attentive to even small changes, as evidenced in the following thoughtful and balanced reflections from participants:

- "Research is serious to me, but maybe it can also be fun, just like using coloured pens to write down whatever you want to write on the fancy papers. I am the one who has the option and can make decision." (k4-1)

- "In the early stages of writing, I can shift attention from the genres, formats, grammars, etc. to my idea development. Free writing is important. Writing is thinking. I don't need to show anyone my first draft. It's for my eyes only. Therefore, I think I do have choices to make, even if I do need to follow certain rules in the later stages." (a6-2)

- "Actually, I didn't put that much effort on writing during the last month, but I am now more confident about how I "can" write rather "should" write." (g6-2)

\subsection{Observations and Discussion}

Whatever else can be said, this kind of intervention achieved its goal of raising students' awareness of their identities as writers, of helping them clarify for themselves what the expectations are of them and their research, and of the choices they make about their writing. The workshop helped them see their research and writing from different perspectives and to attend to things they had not noticed previously. It helped them raise questions about their research topics that they hadn't considered before, and to pay attention to process as much as content.

While at times participants exhibited some discomfort and stress when asked to do things that involved selfreflection or disclosure, there was a visible softening and opening as trust and comfort were built in the group and with the facilitators/researchers. As the sessions progressed participants became more attentive to the process of writing, and able to be creative in focused, structured ways. There were many expressions of openness to new techniques introduced during the sessions, as well as expressions of empowerment, i.e. when they came to know a new technique, they wanted to use it. A key insight was into the difficulties in writing which often came from self-editing too early. Thus, participants understood the importance of just starting, without self-criticism, and the importance of having control and choice, both over the first draft and subsequent revisions. 


\section{CONCLUSIONS}

The "Thinking Creatively about Research" workshops are part of an interdisciplinary instructional development research grant which explores how academic writers of all backgrounds and skill levels might think more clearly about their research, write with impact, demystify the discourse of their discipline, communicate with a more diverse audience, and tap into a deeper well of creative potential.

Those who completed the engineering workshop were enthusiastic and committed. That they continued to come to the workshop sessions despite the significant time commitment speaks to the value participants perceived in the workshop. Moreover, the research data shows that participants experienced growth in writing output, confidence and self-efficacy over the course of the workshop.

Although the "Thinking Creatively About Research" pilot program of workshops was offered to graduate students only in two broad disciplinary areas of the university, there is the potential, based on the results of the pilot program of workshops and its accompanying research study, to expand the offering of the program on an ongoing co-curricular or curricular basis across a wide range of disciplines, to senior undergraduate and graduate students as well as to faculty members and other staff members who need to write on a regular basis as part of their work at the university.

We started the paper with a reference to the heroic journey of completing the writing of a major piece of research. While none of the engineering participants explicitly referred to the journey metaphor in their evaluations of the workshop, it would seem to have been a journey for some. Many small hints suggested change in their writing or their approach to writing, change accompanied by a wider vision-sometimes accompanied by surprise, or a sense of challenge or difficulty, or just a resolute gaze into their academic future. We end with a quote suggesting insight and change, from the evaluations at the end of the seven days of the engineering workshop:

- "It's not just about writing. The techniques are about every aspect in research."

\section{Acknowledgements}

This research has been supported by an Instructional Development Grant from Memorial University of Newfoundland in 2011-2012. We acknowledge with thanks the participation of the Engineering graduate students in the Winter of 2012. Ethical approval for this research was granted by the Interdisciplinary Committee on Ethics in Human Research at Memorial University of Newfoundland.

\section{References}

[1] C. Aitcheson and A. Lee, "Research writing: Problems and pedagogies," Teaching in Higher Education, vol. 11, no. 3. pp. 265-278, 2006.

[2] David V. Anderson, "Storytelling - the missing art in engineering presentations,” IEEE Signal Processing Magazine, Vol. 28, No. 2, pp. 109-111, March 2011.

[3] C.M. Badenhorst, Research Writing: Breaking the Barriers. Pretoria: Van Schaik, 2007, 190 pp.

[4] C.M. Badenhorst, Dissertation Writing: A Research Journey. Pretoria: Van Schaik, 2008, 232 pp.

[5] J. Catterall, P. Ross, C. Aitchinson, and S. Burgin, "Pedagogical approaches that facilitate writing in postgraduate research candidature in science and technology,” Journal of University Teaching and Learning Practice, Vol. 8, no. 2, 2011.

[6] M. Csikszentmihalyi, Flow: The psychology of optimal experience. New York: Harper Perennial, 2008, 303 pp.

[7] Engineering Communication Program, Online Handbook, Toronto: University of Toronto, Faculty of Engineering and Applied Science, Available as of May 17, 2012 at http://www.engineering.utoronto.ca/Directory/students/ecp/h andbook

[8] Thomas C. Erren, Paul Cullen, Michael Erren and Philip E. Bourne, "Ten simple rules for doing your best research, according to Hammond,” PLOS Computational Biology, Vol. 3, Issue 10, pp. 1839-40, Oct 2007. Available as of Feb 21, 2012 from www.ploscompbiol.org/article/info:doi/10.1371/journal.pcbi. $\underline{0030213}$

[9] Alice S. Huang, “Passions,” Science, Vol. 334, pp. 13621366, 9 December 2011. Available as of Feb 21, 2012 from http://www.sciencemag.org/content/334/6061/1362.full.pdf

[10] S. Keshav, "How to read a paper.” Available as of Feb 21, 2012 from

http://blizzard.cs.uwaterloo.ca/keshav/home/Papers/data/07/p aper-reading.pdf

[11] M.R. Lea, “Academic literacies: A pedagogy for course design,” Studies in Higher Education, Vol. 29, No. 6, pp. 739-756, 2004.

[12] M.R. Lea and B.V. Street, "Student writing in higher education: An academic literacies approach," Studies in Higher Education, Vol. 23, No. 2, pp. 157-172, 1998.

[13] M.R. Lea and B.V. Street, "Writing as academic literacies: Understanding textual practices in higher education.” in Writing: Texts, Processes and Practices, C.N. Candlin and K. Hyland (eds.) (London: Longman), pp. 62-81, 1999. 
[14] M.R. Lea and B.V. Street, “The 'academic literacies' model: Theory and applications," Theory into Practice, Vol. 45, No. 4, pp. 368-377, 2006.

[15] T. Lillis and M.Scott, "Defining academic literacies research: Issues of epistemology, ideology and strategy," Journal of Applied Linguistics, Vol. 4, no. 1, pp. 5-32, 2007.

[16] Henrique S. Malvar, "Effective communication: tips on technical writing,” IEEE Signal Processing Magazine, Vol. 25, No. 3, pp. 129-132, May 2008.

[17] T. Malkinson, "Writing is good for your career," IEEE Canadian Review, No. 57, Spring 2008, pp. 29-30.

[18] S.B. Merriam, Qualitative Research: A Guide to Design and Implementation. San Francisco: Jossey-Bass, 2009, 304 pp.

[19] Y. Manolopoulou, "Unformed drawing: Notes, sketches, and diagrams," The Journal of Architecture, Vol. 10, no. 5, pp. 517-525, 2005.

[20] C. Moloney, "Reading, doing, and communicating DSP.” Presented at IEEE Newfoundland Electrical and Computer Engineering Conference 2008, St. John's, NL, Nov 6, 2008. Updated version available as of May 17, 2012 from www.engr.mun.ca/ cmoloney/dsp10Archive/dspsem/ReadDSP etc2010Final.ppt
[21] Scott L. Montgomery, The Chicago Guide to Communicating Science. Chicago: University of Chicago Press, 2003, 228 pp.

[22] Wayne T. Padgett and Mark A. Yoder, "Effective communication: excellence in a technical presentation," IEEE Signal Processing Magazine, Vol. 25, No. 2, pp. 124127, March 2008.

[23] J. Schimel, Writing Science: How to Write Papers That Get Cited and Proposals That Get Funded, Oxford University Press, 2012, 221 pp.

[24] B. Street, "What's 'New' in New Literacy Studies? Critical approaches to literacy in theory and practice," Current Issues in Comparative Education, Vol. 5, No. 2, pp. 77-91, 2003.

[25] B.V. Street, Literacy in theory and practice. Cambridge, UK: Cambridge University Press, 1984, 243 pp.

[26] B.V. Street, Social Literacies: Critical Approaches to Literacy Development, Ethnography and Education. London: Longman, 1995, 184 pp.

[27] M. Young, The Technical Writer's Handbook: Writing with Style and Clarity, Mill Valley, CA: University Science Books, 1989, 232 pp. 